\title{
A CARCINICULTURA NOS MANGUEZAIS DO NORDESTE BRASILEIRO: PROBLEMÁTICAS SOCIOAMBIENTAIS NAS COMUNIDADES TRADICIONAIS
}

\author{
CARCINICULTURE IN THE MANGROVES OF NORTHEASTERN BRAZIL: \\ SOCIOENVIRONMENTAL PROBLEMS IN TRADITIONAL COMMUNITIES
}

João Jorge SILVA-JÚNIOR, Gilberto NICACIO², Gilberto Gonçalves RODRIGUES³

Artigo recebido em 20/05/2020, aceito em 06/10/2020, publicado em 16/12/2020.

\author{
Palavras-chave: \\ Ecossistemas \\ costeiros; \\ Políticas públicas; \\ Áreas protegidas; \\ Injustiça social; \\ Indústria do camarão.
}

Keywords: Coastal ecosystems; Public policies; Protected areas; Social injustice; Shrimp industry.

\section{RESUMO}

A carcinicultura nos manguezais promovem conflitos socioambientais entre empresários da indústria do camarão e as comunidades tradicionais pelo direito ao uso e acesso dos recursos naturais nesses ecossistemas. Este estudo analisou os cenários dessa atividade econômica mediante revisão bibliográfica das problemáticas relacionadas à indústria do camarão no Nordeste do Brasil. Em geral, a ineficiência da legislação ambiental para gestão de conflitos, a falta de uma gestão ambiental justa e participativa e a falta de representatividade das comunidades tradicionais na solução desses problemas têm permitido que os impactos ambientais gerados sejam agravados socialmente. Dessa forma, a degradação dos manguezais pela supressão da vegetação e a descarga de efluentes poluentes nos estuários têm sido destacadas como as principais ameaças às atividades das comunidades tradicionais.

\section{ABSTRACT}

Carciniculture in mangroves promotes socio-environmental conflicts between shrimp industry entrepreneurs and traditional communities for the right to use and access natural resources in these ecosystems. This study analyzed the scenarios of this economic activity through a bibliographic review of the problems related to the shrimp industry in Northeast Brazil. In general, the inefficiency of environmental legislation for conflict management, the lack of fair and participatory environmental management, and the lack of representativeness of traditional communities in solving these problems have allowed the environmental impacts generated to be socially aggravated. Thus, the degradation of mangroves by the suppression of vegetation and the discharge of polluting effluents into the estuaries have been highlighted as the main threats to the activities of traditional communities.

\footnotetext{
1 Graduado em Ciências Biológicas com ênfase em Ciências Ambientais pela Universidade Federal de Pernambuco.

E-mail: joaojorge.ccb@gmail.com.

2 Doutor em Zoologia pela Universidade Federal do Pará. E-mail: gilnicacio@gmail.com

${ }^{3}$ Professor do Departamento de Zoologia, Centro de Biociências da Universidade Federal de Pernambuco.

E-mail: gilbertorodrigues.ufpe@gmail.com
} 


\section{INTRODUÇÃO}

O manguezal representa um ecossistema único que oferece condições ideais para a reprodução, desenvolvimento e manutenção de muitas espécies estuarinas e marinhas (Pinto et al., 2013). As áreas de mangue são responsáveis pela ciclagem, processamento e manutenção dos sedimentos que fazem parte das dinâmicas dos ambientes terrestres e marinhos. Donato et al. (2011) destacam que as florestas de manguezais estão entre as mais ricas em carbono nos trópicos e que o desmatamento destas áreas gera o equivalente a $10 \%$ das emissões de carbono do desmatamento global, sendo consideradas áreas prioritárias para conservação e estudo dos cenários de mudanças climáticas.

Segundo Santos, Santos \& Almeida (2016), os manguezais podem ser apontados como indicadores biológicos para registro das modificações da linha de costa por sua sensibilidade às alterações climáticas e aos efeitos das ações humanas. No âmbito geral, a manutenção de todos esses serviços ecossistêmicos e ambientais providos pelo manguezal depende da interação entre a sociedade e o meio ambiente, que envolvem a tomada de decisão necessária para a gestão sustentável desses ecossistemas, seja pelo setor público que atuam nessas áreas ou pelos atores locais que lidam diretamente com o manguezal e fazem uso dos seus recursos. Além da sua notável importância ambiental, os manguezais contribuem com recursos naturais para as populações humanas e são importantes territórios onde vivem as comunidades locais pesqueiras (Malik, Fensholt \& Mertz, 2015).

Considerando o uso dos recursos originados nos manguezais, Carneiro, Farrapeira \& Silva (2008) observaram que as comunidades de pescadores artesanais utilizam os recursos do manguezal para a sobrevivência, aplicando conhecimentos e técnicas para obtenção desses recursos que geralmente são repassados aos descendentes. Em geral, a cultura local dessas comunidades visa a manutenção do ecossistema de manguezal, uma vez que a preservação de práticas que garantam o uso dos recursos sem levar ao esgotamento, mostra-se fundamental para que os descendentes conservem os recursos dos quais dependem para a sua sobrevivência.

Apesar destes esforços, as comunidades pesqueiras que sobrevivem dos recursos do mangue são frequentemente expostas às problemáticas econômicas e políticas que comumente promovem à degradação e a redução das suas áreas de uso para pesca nas regiões de manguezal. Isto por que, diversas atividades ligadas ao uso do solo nestas regiões causam impactos a estes ecossistemas, pois são comumente instaladas em suas regiões de entorno ou até mesmo inseridas no interior das áreas de mangue. Dessa forma, a implantação de atividades econômicas podem ser apontadas como uma das principais problemáticas causadoras de conflitos socioambientais e de degradação dos habitas nesses ambientes.

Entre as atividades econômicas causadoras de conflitos socioambientais e de degradação dos habitas nos manguezais, a indústria do camarão pode ser destacada como uma das atividades mais geradoras de problemáticas associadas à insustentabilidade social, econômica e ambiental. Em um cenário global, o cultivo de camarão em fazendas e viveiros é uma atividade praticada em diversos países, principalmente na Ásia e 
América Latina por possuírem regiões estuarinas com condições climáticas consideradas ideais para 0 desenvolvimento das espécies comercialmente viáveis (Carvalho \& Martins, 2017). Nesta indústria, as principais espécies são de crustáceos decápodes como o camarão branco do Pacífico Litopeneaus vannamei e o Macrobrachium rosenbergii conhecido também pelos nomes comuns de camarão-da-malásia, lagostim-deágua-doce e camarão-gigante-da-malásia (Oliveira \& Mattos, 2007).

No Brasil, a produção de camarão ficou mais notável em 2003, quando sua produção cresceu de 3.600 toneladas em 1997 para 90.190 toneladas em 2003, assim como as exportações de US\$2,8 milhões em 1998 para US\$ 427,92 milhões em 2003 (Rocha, 2015). No Nordeste do Brasil, responsável por 97\% da produção nacional podem ser destacadas as características climáticas, topográficas e hidrobiológicas, benéficas ao cultivo durante todo 0 ano. Por isso, os investimentos em infraestrutura na região associados à queda na produção mundial aumentaram os investimentos no setor (Figueirêdo, Rosa \& Godim, 2003). A maioria dos empreendimentos de camarão no Brasil utiliza pós-larvas produzidas em laboratórios especializados, do camarão L. vannamei e cultivam em duas etapas: (i) larvicultura e a (ii) engorda (Natori, Sussel \& Gameiro, 2011). Com a introdução da espécie exótica de camarão L. vannamei, foram gerados melhores resultados na produção que causou aceleração no crescimento de empreendimentos ampliando a construção de viveiros para produção, em muitos casos localizados no interior de áreas de manguezais (Jeronimo \& Balbino, 2012).

Essa ampliação da atividade tem sido apontada como as principais causas de impactos ambientais, pois está associada ao aumento de áreas para aumento das fazendo para atender diferentes etapas de produção. Isto por que, o ciclo de vida das espécies cultivadas inclui a implantação de viveiros para 0 desenvolvimento das larvas, onde ocorre destruição de áreas de manguezal para conversão de planícies em viveiros, em seguida observa-se a etapa de operação e engorda associada ao descarte de efluentes provenientes das rações. Nessas etapas, há riscos de impactos ambientais como uso excessivo de água do ecossistema, escapes de indivíduos e o lançamento de efluentes tóxicos como o metabissulfito de sódio (Dias, Soares \& Neffa, 2012).

De acordo com a legislação brasileira, as fazendas para carcinicultura deveriam se estabelecer em áreas de apicuns ou salgados para realização da atividade segundo a Lei 12.651/2012 (Brasil, 2012). No entanto, em sua grande maioria, esses empreendimentos se instalam em manguezais com a supressão da mata de mangue para o construção dos viveiros de produção. Fabiano (2004) afirma que o funcionamento de fazendas de carcinicultura encontra-se intimamente relacionado à degradação intensiva e descontrolada dos ecossistemas costeiros. Isso se dá em decorrência dos diferentes graus de impacto da cadeia produtiva da carcinicultura, que segundo Tancredo, Nobrega \& Lapa (2011), envolve os processos de produção de insumos, da larvicultura, das fazendas de engorda, empresas de beneficiamento e das indústrias químicas que utilizam como matérias-primas os resíduos do camarão. Assim, em todos esses processos é possível apontar problemáticas associadas aos impactos ambientais e sociais. No Brasil, a legislação sobre carcinicultura surgiu 
em 2002, quando muitos empreendimentos já estavam estabelecidos fazendo com que houvesse um trabalho retroativo por parte dos órgãos reguladores (D'angelis \& Moura, 2016).

A Resolução NR. 312, de 10 de outubro de 2002 do Conselho Nacional do Meio Ambiente (CONAMA) em seu artigo $2^{\circ}$ dispõe que é vedada a prática da carcinicultura em áreas de manguezal e que a atividade dos empreendimentos de carcinicultura na zona costeira deve ser licenciada por meio de procedimento de licenciamento ambiental (Araripe, Lopes \& Bastos, 2006). Entretanto, a mesma é observada inavadindo áreas de manguezais na costa brasileira como resultado de diversos conflitos de interesse que em geral favorecem os agentes da indústria em detrimento dos impactos ambientais negativos já conhecidos.

Em 2005, no litoral norte de Pernambuco, a carcinicultura já era responsável pela perda de $9,6 \%$ dos manguezais (Guimarães, 2007). Segundo o ICMBIO (2018), os manguezais têm sido degradados de forma significativa e $25 \%$ desse ecossistema pode já ter sido perdido no país, devido principalmente à carcinicultura e ao desenvolvimento costeiro inadequado. Para Tancredo, Nobrega \& Lapa (2011), os principais impactos ambientais negativos gerados pela carcinicultura são a (i) supressão da vegetação para implantação dos viveiros - causando perda da biodiversidade, (ii) ocupação da faixa de praia com impacto visual, (iii) lançamento de efluentes ricos em matéria orgânica diretamente no estuário - promovendo processos de eutrofização, (iv) efluentes de tratamentos microbiológicos, (iv) lançamento de efluentes contendo metabissulfilto de sódio, utilizado na despesca poluindo os cursos de água, (v) escape de espécies exóticas para o estuários e (vi) consumo de grandes volumes de água dos rios.

Somados a esses impactos ambientais, estão os impactos socioambientais enfrentados pelas comunidades tradicionais pesqueiras que estão expostas aos problemas ambientais e também sofrem pelas limitações nas suas áreas de uso dos recursos pesqueiros. Pinto et al. (2013) chamam a atenção para o fato de que a carcinicultura em áreas de manguezais descaracteriza o meio ambiente, dificultando o processo de definição de ecozonas ou locais diferenciados para práticas das comunidades tradicionais, comprometendo 0 uso sustentável e causando problemáticas socioambientais nestes ecossistemas. Assim, alternativas mitigadoras aos impactos socioambientais da carcinicultura são essenciais para propostas de gestão adequada dessa atividade.

Miranda, Alencar \& Silva (2016) apontam que conflitos socioambientais em áreas de mangue, envolvendo a carcinicultura, estão associados à perda da identidade cultural das comunidades tradicionais, uma vez que têm suas práticas restringidas, comprometendo sua estrutura social, econômica e cultural. Araruna \& Soares (2017) sugerem que, em áreas protegidas, a gestão deveria estar associada aos conflitos socioambientais no que diz respeito à sua eficiência na fiscalização do uso da terra.

Assim, para ampliar a discussão sobre a indústria do camarão nos manguezais do Nordeste do Brasil, foi realizada uma revisão da literatura procurando (i) identificar os impactos ambientais da carcinicultura em manguezais do Nordeste do Brasil; (ii) identificar os conflitos socioambientais da carcinicultura nos manguezais o Brasil e (iii) problemáticas da carcinicultura relacionadas às comunidades tradicionais. 


\section{MÉTODO}

Esta pesquisa teve caráter exploratório e descritivo. Para obtenção da literatura relacionada ao tema do objetivo, foi realizada uma busca sobre artigos disponíveis na base de busca da página do Portal de Periódicos CAPES. Não houve filtro de ano das publicações. Utilizou-se o mesmo portal para busca de outros documentos relacionados ao tema para discussão como teses, dissertações e anais de eventos. Também foram consultados documentos oficiais, Leis e Resoluções pertinentes.

Inicialmente utilizou-se a palavra-chave em português "carcinicultura" para pesquisa de artigos. Para direcionar de maneira estrita a busca às pesquisas relacionadas ao tema, uma vez que o termo "carcinicultura" é aplicável a outros crustáceos, os seguintes critérios foram utilizados para filtrar a busca como os (a) estudos realizados no Brasil, (b) estudos que demonstraram ou citaram impactos ambientais relacionados à criação de camarão em áreas de manguezal e (c) sua relação com as comunidades tradicionais envolvidas.

A análise dos dados obtidos a partir desta revisão da literatura foi realizada numa perspetiva qualitativa buscando responder aos objetivos relacionando impactos e conflitos socioambientais da carcinicultura às problemáticas das comunidades tradicionais.

\section{RESULTADOS E DISCUSSÃO}

\subsection{Os impactos ambientais da carcinicultura}

Os estudos analisados mostraram um universo diverso de impactos ambientais promovidos pela atividade da carcinicultura estuarina que repercutem negativamente na estrutura de todo o ecossistema manguezal e na sociedade. 0 descarte irregular de efluentes diretamente no estuário juntamente com a supressão das matas de mangue para instalação dos viveiros de camarão foram os temas mais frequentes, somando oito (8) estudos cada um.

Foram verificados os seguintes indicadores de impactos nos estudos: quatro (4) artigos sobre erosão e assoreamento, três (3) artigos sobre eutrofização, perda de recursos naturais e perda de serviços ecossistêmicos, dois (2) artigos sobre toxicidade dos produtos químicos utilizados na despesca em espécies do manguezal e desequilíbrio trófico, e por último, um (1) artigo para salinização dos solos e represamento de águas, conforme o Quadro 1.

\subsection{A natureza dos conflitos socioambientais na carcinicultura}

Do universo analisado, seis (6) artigos versam sobre os conflitos socioambientais pelo uso das áreas do ecossistema manguezal nos Estados do Rio Grande do Norte, Ceará e Bahia; três (3) artigos sobre conflitos pelo uso dos recursos naturais como os cursos de água, utilizados em algumas localidades para irrigação ou abastecimento nos Estados do Ceará e Rio Grande do Norte; um (1) sobre gestão de UCs por órgãos oficiais e um (1) conflito por falta de regulamentação de efluentes (Quadro 2). 
Quadro 1 - Impactos ambientais da carcinicultura em áreas de manguezal no Brasil.

\begin{tabular}{|c|c|c|c|}
\hline Impactos ambientais & $\mathrm{N}^{0}$ artigos & Localidades & Fonte bibliográfica \\
\hline Descarte de efluentes & 8 & $\begin{array}{l}\text { Guamaré-RN, Aracaú-CE, } \\
\text { Mossoró-RN, Russas-CE. }\end{array}$ & $\begin{array}{l}\text { Ferreira, Melo, \& Costa Neto } \\
\text { (2008); Elfes et al. (2014); } \\
\text { Loureiro \& Gorayeb (2013); } \\
\text { Laurentino \& Souza (2013); } \\
\text { Godoy \& Lacerda (2014); Gomes, } \\
\text { Batista, \& Lima (2018); Nóbrega } \\
\text { et al. (2013). }\end{array}$ \\
\hline Supressão do Manguezal & 8 & $\begin{array}{l}\text { Costa-CE, Nísia Floresta-RN, } \\
\text { Nísia Floresta-RN, Mossoró- } \\
\text { RN }\end{array}$ & $\begin{array}{l}\text { Godoy \& Lacerda (2014); Godoy, } \\
\text { Meireles, \& Lacerda (2018); Mota, } \\
\text { Schmitz, \& Silva-Júnior (2015).; } \\
\text { Nóbrega et al. (2013); Oliveira \& } \\
\text { Mattos (2007); Elfes et al. (2014); } \\
\text { Laurentino \& Souza (2013). }\end{array}$ \\
\hline Erosão e assoreamento & 4 & $\begin{array}{l}\text { Mossoró-RN, Russas-CE, } \\
\text { Laguna de Guaraíras-RN, } \\
\text { Aracati-CE. }\end{array}$ & $\begin{array}{l}\text { Godoy \& Lacerda (2014); } \\
\text { Laurentino \& Souza (2013); } \\
\text { Gomes, Batista, \& Lima (2018); } \\
\text { Godoy, Meireles, \& Lacerda } \\
\text { (2018); Elfes et al. (2014). }\end{array}$ \\
\hline Eutrofização & 3 & Aracaú-CE e Aracatí-CE. & $\begin{array}{l}\text { Tuna \& Tagliolatto (2015); } \\
\text { Nóbrega et al. (2013); Godoy \& } \\
\text { Lacerda (2014); Godoy, Meireles, } \\
\text { \& Lacerda (2018). }\end{array}$ \\
\hline $\begin{array}{l}\text { Perda de recursos e serviços } \\
\text { ecossistêmicos }\end{array}$ & 3 & Aracaú-CE e Aracatí-CE. & $\begin{array}{l}\text { Godoy \& Lacerda (2014); Loureiro } \\
\text { \& Gorayeb (2013); Tuna \& } \\
\text { Tagliolatto (2015); Nóbrega et al. } \\
\text { (2013). }\end{array}$ \\
\hline Toxicidade de espécies & 2 & Bragança-PA e Abrolhos-BA & $\begin{array}{l}\text { Pedale, Fujimoto, \& Abrunhosa } \\
\text { (2012); Galli, Fujimoto, \& } \\
\text { Abrunhosa (2012). }\end{array}$ \\
\hline Desequilíbrio trófico & 2 & Goiana-PE. & $\begin{array}{l}\text { Araújo, Nascimento, \& Oliveira } \\
\text { (2016); Tuna \& Tagliolatto (2015). }\end{array}$ \\
\hline Salinização do solo & 1 & Guamaré-RN & $\begin{array}{l}\text { Ferreira, Melo, \& Costa Neto } \\
\text { (2008). }\end{array}$ \\
\hline Represamento de águas & 1 & Goiana-PE & $\begin{array}{l}\text { Araújo, Nascimento, \& Oliveira } \\
\text { (2016). }\end{array}$ \\
\hline
\end{tabular}

\subsection{Os impactos socioambientais e os fatores sociais}

A descarga de efluentes não tratados no meio ambiente representa um dos maiores impactos socioambientais causados pela atividade da carcinicultura, pois poluem cursos d'água, muitas vezes utilizados para pesca, abastecimento, irrigação, pecuária (Ferreira, Melo \& Costa Neto, 2008). Os efluentes não tratados descarregados diretamente no estuário afetam o funcionamento e manutenção dos processos geoquímicos nos solos do manguezal, segundo Nóbrega et al. (2013), que determinou os impactos desses efluentes sobre 0 ferro e o enxofre, elementos importantes no processo de decomposição de matéria orgânica.

A dimensão dos efeitos dos efluentes pode ser percebida através do estudo de Silva (2009), que analisou a dinâmica da carcinicultura presente na área da APA de Mamanguape-PB e verificou que uma usina apresentava vários conflitos ambientais relacionados com a carcinicultura. Esta atividade promoveu impactos 
ambientais no que diz respeito a alterações no fluxo de marés e lançamento de efluentes, provenientes da despesca dos viveiros de camarão, comprometendo uma área de 63,8 ha do manguezal.

Quadro 2 - Conflitos socioambientais na carcinicultura presentes nos artigos revisados.

\begin{tabular}{|l|c|l|l|}
\hline Tipo de conflito socioambiental & $\begin{array}{c}\mathbf{N}^{0} \\
\text { artigos }\end{array}$ & \multicolumn{1}{|c|}{ Localidades } & \multicolumn{1}{|c|}{ Fonte bibliográfica } \\
\hline Pelo uso da área & 6 & $\begin{array}{l}\text { Nova Viçosa-BA, } \\
\text { Aracaú-CE, } \\
\text { Guaraíras-RN. }\end{array}$ & $\begin{array}{l}\text { Dias, Soares, \& Neffa (2012); Loureiro \& } \\
\text { Gorayeb (2013); Gomes, Batista, \& Lima } \\
(2018), \text { Tuna \& Tagliolatto (2015), Elfes et al. } \\
\text { (2014); Rocha (2015). }\end{array}$ \\
\hline $\begin{array}{l}\text { Pelo uso dos recursos (irrigação/ } \\
\text { abastecimento de água) }\end{array}$ & 3 & $\begin{array}{l}\text { CE, Vale do Rio } \\
\text { Açú-RN, Russas- } \\
\text { CE. }\end{array}$ & $\begin{array}{l}\text { Mota, Schmitz \& Silva-Júnior (2015); } \\
\text { Carvalho \& Martins (2017); Leitão et al. } \\
\text { (2011). }\end{array}$ \\
\hline $\begin{array}{l}\text { Na gestão de UCs por órgãos } \\
\text { oficiais }\end{array}$ & 1 & $\begin{array}{l}\text { APA Delta do } \\
\text { Parnaíba (PI-CE- } \\
\text { MA). }\end{array}$ & \begin{tabular}{l} 
Araripe, Lopes \& Bastos (2006). \\
\hline Regulamentação de efluentes
\end{tabular} \\
\hline
\end{tabular}

Fonte: Autores, 2018.

Além do impacto direto ao meio ambiente, de acordo com Amorim (2011), o descarte de efluentes também pode ser considerado como gerador de conflitos socioambientais entre fazendeiros e comunidades tradicionais. Um dos motivos para o problema dos efluentes, certamente, está relacionado com a regulamentação, como visto por Azevêdo (2005) em que a legislação de licenciamento é sofrível quanto ao controle de contaminação química de efluentes da carcinicultura.

Fernandez (2015) destaca, como exemplo, a presença de uma enorme fazenda de carcinicultura com cerca de 560 ha no centro da RESEX Acaú-Goiana, Estado de Pernambuco, que foi considerada pela comunidade como um "desastre ambiental" com repercussões negativas no manguezal que teve sua área suprimida, nos cursos de água por conta dos resíduos dos efluentes e na relação entre os seguranças da fazenda e os pescadores. Ambas as localidades na APA de Mamanguape e na RESEX Acaú-Goiana foram visitadas para reconhecimento das atividades.

A supressão da vegetação do manguezal é outro impacto socioambiental importante no contexto da atividade da carcinicultura em manguezais, uma vez que, desestrutura todo o ecossistema gerando uma cascata de eventos ecológicos associados. De acordo com Silveira, Mesquita, \& Oliveira Filho (2013), a implantação da carcinicultura foi responsável pela supressão de verdadeiras "ilhas plenas de florestas" no estuário do Rio Goiana, nos estados de Pernambuco e Paraíba. Além disso, a carcinicultura comprometeu 0 
acesso dos catadores e pescadores tradicionais ao manguezal, desviou e poluiu cursos d'água através da descarga de efluentes não tratados diretamente no estuário.

Da mesma forma, Rodrigues et al. (2017) observaram que esse impacto compromete a ecologia do manguezal e a autonomia pesqueira e cultural das comunidades tradicionais. Depreende-se através desses estudos que a carcinicultura está diretamente ligada tanto aos problemas ambientais quanto aos sociais. Isso fica claro através do estudo de Dias, Soares \& Neffa (2012), sobre o imbróglio ambiental causado pela possibilidade da instalação de um empreendimento de carcinicultora numa área de 1500 ha de restinga arbustivo-herbácea e manguezais no complexo estuarino de Caravelas, na Bahia, com repercussão direta para cerca de 2450 pessoas.

Uma das consequências diretas da supressão das matas de manguezais é a erosão dos solos, que por sua vez, se relaciona com processos de assoreamento de rios e canais de marés dos manguezais. Godoy, Meireles \& Lacerda (2018) verificaram que as fazendas de camarão (depois das fazendas de agricultura e do escoamento urbano) contribuem para o processo de assoreamento dentro do estuário. Um dos motivos para ocorrer 0 assoreamento dos rios e canais diz respeito à transferência da areia da praia para, pelos ventos, para o leito dos rios devido à ausência da vegetação protetora (Laurentino \& Souza, 2013).

Outros problemas citados no mesmo estudo apontam para problemas relacionados à navegabilidade $\mathrm{e}$ redução do potencial de pesca, trazendo à tona a questão socioambiental e mostrando um impacto real para comunidades que utilizam os leitos dos rios para atividades de subsistência. Além disso, a descarga de sedimentos ricos em matéria orgânica diretamente no estuário permite que estes sejam consumidos no meio ambiente podendo provocar eutrofização, mais um problema verificado na revisão realizada.

O problema da eutrofização também foi verificado na APA de Mamanguape no Estado da Paraíba por Silvestre, Farias \& Braga (2011), que observaram processos de eutrofização resultantes do uso de ração nos viveiros de camarão, os quais poderiam causar desequilíbrios ambientais. Essas rações são ricas em elementos químicos que favorecem os processos de eutrofização, como $\circ \mathrm{N}$ e $\circ \mathrm{P}$, são a origem de um dos principais problemas encontrados na descarga de nutrientes nos viveiros, que são utilizados principalmente para engorda dos camarões e/ou para a despesca.

O conjunto dos impactos citados acima contribui para a perda dos recursos ambientais e serviços do ecossistema, outro ponto abordado durante a revisão e visitas realizadas. Loureiro \& Gorayeb (2013) destacam as alterações que a carcinicultura promove em ambientes com potenciais recursos naturais e paisagísticos que podem ser utilizados pela sociedade para exploração marinha e extrativismo vegetal. Segundo Lima (2016), o manguezal é impactado pela privatização de suas áreas onde, a partir do interesse econômico, são realizadas atividades de carcinicultura, muitas vezes deferidas oficialmente pelo poder público, que causam impactos ao ecossistema e repercutem negativamente na qualidade de vida da comunidade local causando escassez dos recursos naturais. Em estudo sobre os impactos nos recursos hídricos do Município de Goiana, litoral norte de Pernambuco, 
Araújo, Nascimento \& Oliveira (2016) levantam a questão da "ética fundamental para a sustentabilidade socioambiental" ao constatar que a atividade da carcinicultura também leva as comunidades locais a um estado de vulnerabilidade socioambiental pela sua exposição aos cursos d'água poluídos comprometendo sua saúde e o ecossistema do qual dependem para sobreviver.

Considerando o metabissulfito de sódio, um agente químico utilizado na carcinicultura do camarão na prevenção da mancha negra, Pedale, Fujimoto \& Abrunhosa (2012) alertam para a toxicidade desse composto inorgânico sobre outros crustáceos como o caranguejo-uçá (Ucides cordatus), que apresentou sensibilidade e toxicidade aguda a este efluente químico liberado durante a despesca do camarão. Esse estudo, realizado em Bragança-PA, alerta para a toxicidade aguda do caranguejo-uçá nas suas formas adultas e juvenis coletadas às margens dos rios sob impactos de efluente químicos, sugerindo inclusive que devido à sua sensibilidade ao poluente, o mesmo pode ser utilizado no biomonitoramento ambiental em áreas com atividades da carcinicultura. Assim, os impactos ambientais dessa atividade têm efeito direto na queda do seu estoque nos manguezais em resposta aos agentes poluentes como o metabissulfito de sódio.

Alves \& Nishida (2003) destacam que impactos ambientais sobre as populações do caranguejo-uçá nos manguezais traz efeitos sociais sob o ponto de vista econômico, pois trata-se de um recurso importante para a economia local, principalmente para comunidades tradicionais e pescadores artesanais. Em estudo similar em Caravelas na Bahia, Galli, Fujimoto \& Abrunhosa (2012) também observaram efeitos nocivos do metabissulfito de sódio sobre o guaiamum, Cardisoma guanhumi, indicando que as larvas e pós-larvas de indivíduos desta espécie são expostas à altas mortalidades, mesmo na presença de pequenas concentrações desse agente químico que também provoca mudanças nas concentrações de oxigênio dissolvido e altera o pH da água.

Outra problemática ambiental relacionada à carcinicultura é resultada do represamento das águas para utilização nos viveiros que tem sido associada a desequilíbrios tróficos nos manguezais. Moreira et al., (2018) e Tuna \& Tagliolatto (2015) comentam que a eutrofização tem gerado perda de serviços ecossistêmicos dos manguezais, alteração da cadeia trófica estão relacionados ao represamento de águas que gera a interrupção ou mudança do fluxo de nutrientes desequilibrando a cadeia alimentar.

Um outro impacto que pode ser destacado como resultado da carcinicultura é relacionado à salinização do solo e das águas próximas às fazendas de camarão. Segundo Ferreira, Melo \& Costa Neto (2008), a salinização afeta as propriedades físico-químicas do solo e da água, prejudicando possíveis atividades agrícolas nas áreas de entorno e acelerando processos de desertificação nestas regiões. Dessa forma, estágios avançados dos processos de hipersalinização nos solos dos manguezais podem afetar dinâmicas de restauração natural dos manguezais (Andrade et al., 2007).

Estas problemática adicionam questões decisivas nos processos de descaracterização das atividades pesqueiras das comunidades tradicionais uma vez que o estoque de recursos pesqueiros pode ser afetado por esses impactos e afetar a produtividade dos pescadores artesanais. 


\subsection{0 fator socioambiental da carcinicultura}

A carcinicultura comercial presente, principalmente, nos manguezais do Nordeste do Brasil tem se intensificado ao longo dos anos. Como se justificasse, o poder econômico da atividade se utiliza do discurso de um possível "desenvolvimento sustentável" da atividade para crescimento da economia e geração de empregos em detrimento de toda uma estrutura ambiental, social e cultural que envolve a implantação da carcinicultura nesse ecossistema.

Sampaio, Costa \& Sampaio (2008) analisaram impactos socioeconômicos da carcinicultura em dez municípios nos Estados da Bahia, Ceará, Pernambuco, Piauí e Rio Grande do Norte, e destacam efeitos positivos para a elevação da oferta de empregos, renda, receitas municipais e qualidade de vida local. Ao contrário, Motta-Sobrinho \& Andrade (2011) citam a carcinicultura como um dos principais causadores de conflitos ambientais associados ao uso e ocupação do solo. Estes autores destacam conflitos ao definir: "0 manguezal do Pina em Recife, PE (Ilha de Deus) sofre reflexo de um novo modo de regulação da Cidade do Recife chamado de Chantagens locacional no plano subnacional", uma espécie de exigência dos empresários de flexibilização de normas ambientais em troca de "benefícios" locais como geração de empregos.

Joventino \& Mayorga (2008) adicionam que a geração de empregos desta atividade pode chegar a ser de até $90 \%$ de trabalhadores informais, portanto sem direitos trabalhistas. Santos, Santos \& Holanda (2011) apontam que programas de desenvolvimento regional seguem um contexto fora da realidade sociocultural local, o que gera conflitos socioambientais. Isto por que o reordenamento do território imposto por atividades como a carcinicultura acaba por expropriar as comunidades tradicionais dos seus locais de trabalho (Mota, Schmitz \& Silva-Júnior, 2015).

No que diz respeito ao uso da área, os conflitos socioambientais da carcinicultura em manguezais corroboram a definição de Little (2001), ou seja, estão associadas ao controle dos recursos naturais e ecossistemas, ao uso dos conhecimentos ambientais e aos impactos ao meio ambiente. Isto fica evidenciado no Caso de Município de Caravelas, Bahia, em que o setor empresarial, comunidade de pescadores e marisqueiras apoiada por técnicos de órgãos ambientais, ONGs locais, nacionais e internacionais, pesquisadores de Universidades Federais, Organizações coletivas (associação e sindicatos) e Poder Público mantiveram um conflito que resultou na Criação da RESEX de Cassurubá, BA e impedimento de instalação de empreendimento carcinicultor na área (Dias, Soares \& Neffa, 2012).

O comprometimento sociocultural das comunidades a partir de atividades como a carcinicultura pode ser verificado no conflito do município de Aracati, Ceará, travado entre a Companhia de Água e Esgoto do Estado do Ceará (CAGECE), empresários e trabalhadores da carcinicultura e energia eólica, comunidade pesqueiras, e Poder Público em que a áreas de manguezal e campos de dunas são privatizadas e contaminadas inviabilizando a cultura ancestral das comunidades (Pinto et al. 2013). 
O estuário do Rio Paraíba, abrangendo os municípios de Bayeux, João Pessoa e Cabedelo, também foi palco de conflitos com proprietários das usinas de cana-de-açúcar e fazendas de camarão que, ao utilizarem os manguezais, promoveram desmatamento e outros impactos comprometendo os contextos ecológicos e de subsistência das comunidades tradicionais numa completa "degradação socioambiental" (Silva, 2011).

Bento (2012) analisou um conflito existente entre pescadores, Poder Público em suas diversas esferas e Ambientalistas sobre o crescimento da atividade de Carcinicultura com instalações de viveiros em áreas de preservação permanente de manguezais no Parque dos manguezais e llha de Deus, Recife, Pernambuco. 0 conflito desencadeou em 2003, na audiência pública com CPRH, ambientalistas, academia e deputados para tratar do tema, assim como a criação do Parque Natural Municipal dos Manguezais Josué de Castro (PNMMJC).

A atividade da carcinicultura, neste caso, de caráter tradicional, em que havia comprometimento da comunidade pelo uso sustentável, seria comprometida com a criação do Parque e impedimento das atividades comprometendo as atividades da população ribeirinha. A situação atual após o golpe $2016 \mathrm{com}$ a perda da democratização do Brasil, incentivou atitudes devassas e ampliação dos viveiros de camarão em áreas de manguezal anteriormente recuperadas.

A situação do PNMMJC está à deriva das conjecturas impostas pela governança federal desde os primórdios pré-eleição 2018. Observou-se a ampliação das atividades de beneficiamento de sururu (cocção) em áreas de franjas de manguezal, ampliação de viveiros de camarão, técnicas não sustentáveis de cultivo de camarão, com adição de ração a base de N e P; criação de porcos e outras atividades degradantes foram a constatadas desde a ameaça as instituições e lideranças ambientais presentes.

Sobre a gestão de áreas protegidas, Araripe, Lopes \& Bastos (2006) discutem que há uma gestão ineficiente do poder público quanto às zonas econômicas especiais ZEE, como as áreas costeiras, unidades de conservação e bacias fluviais, a sobreposição de licenças para carcinicultura (licença de instalação antes da licença prévia). Assim, a falta de entendimento entre os órgãos oficiais de meio ambiente, fomento, pesquisa, controle de qualidade voltada à exportação de produtos pesqueiros e sanidade animal, todos fatores geradores de conflitos socioambientais que na prática, na maioria das vezes, favorecem atividades em situação irregular em detrimento de comunidades tradicionais.

Nesse sentido, observa-se que a carcinicultura tem um caráter negativo, do ponto de vista socioambiental uma vez que, como ocorre em vários setores da economia e política brasileiras, o apelo do mercado pelo lucro leva grande vantagem sobre todas as questões ambientais e sociais. Isso pôde ser constatado pela ineficiência das leis nos processos de licenciamento e fiscalização das atividades, pelos conflitos de leis estaduais e federais sobre o mesmo tema e principalmente pela exclusão das comunidades tradicionais na discussão dos seus próprios futuros. Mais uma vez, por conta da legislação ambiental a respeito da sobreposição de área de relevante interesse ecológico, na Área de proteção ambiental e nas Terras Indígenas Potiguaras, foi verificado entre 2007 e 2008 na APA da Barra do Rio Mamanguape, um conflito entre 
carcinicultores e o IBAMA em torno da liberação desta atividade numa área onde se localiza uma importante vegetação de mangue (Moreira \& Andrade, 2010).

A problemática em questão refere-se às competências institucionais na área, uma vez que na APA Mamanguape a competência para a autorização da atividade é do IBAMA, já na Reserva indígena potiguar a competência é da FUNAI. Assim, para os moradores locais isso torna-se um conflito de natureza maior, onde a atividade é vista como de grande impacto em uma área e a poucos quilômetros como atividade geradora de renda, não sendo caracterizada como de impacto aos ecossistemas.

\section{CONCLUSÃO}

Os conflitos socioambientais mencionados no estudo mostraram um pouco da realidade das comunidades tradicionais frente à atividade da carcinicultura. Conflitos pelo uso das áreas e dos recursos naturais, conflitos na gestão de UCs por órgãos oficiais e por falta de regulação de efluentes sinalizam para a complexidade do tema. A literatura revisada por pares do Portal de Periódicos Capes, utilizada na pesquisa, não esgotou as informações verificadas na literatura geral sobre os conflitos socioambientais envolvendo a carcinicultura e suas repercussões nos manguezais e comunidades tradicionais. Entretanto, foi o suficiente para caracterizar a relação entre a atividade da carcinicultura nos manguezais do Nordeste do Brasil e sua influência na estrutura sociocultural das comunidades tradicionais.

A partir dos conflitos foram destacados os principais impactos socioambientais que justificam um caráter negativo da carcinicultura sobre a estrutura socioambiental. Os impactos provenientes da atividade da carcinicultura (criação de camarão em viveiros) podem promover a descaracterização ambiental do manguezal e sociocultural das comunidades envolvidas, mostrando que a legislação pertinente muitas vezes não é respeitada e o poder público não tem força para garantir o seu cumprimento. Por outro lado, a pesquisa mostrou que as comunidades tradicionais ficam no "vácuo" da gestão do meio ambiente que lhes garante a própria existência, sugerindo a realização de mais estudos sobre gestão de áreas protegidas e manutenção da identidade cultural das comunidades tradicionais.

Os desdobramentos desta pesquisa sinalizam para realização de estudos sobre o manejo exemplar do ecossistema manguezal no Brasil e no mundo, processos de sucessão secundária de espécies de mangue em ecossistemas urbanos, programas de inserção das comunidades na gestão de áreas protegidas e tecnologias limpas e sustentáveis para a carcinicultura.

\section{REFERÊNCIAS}

Alves, R. R. N., Nishida, A. K. (2003). Aspectos socioeconômicos e percepção ambiental dos catadores de caranguejo-uçá Ucides cordatus (L. 1763) (Decapoda, Brachyura) do estuário do rio
Mamanguape, Nordeste do Brasil. Interciencia, 28(1), 36-43.

Amorim, D.M.C.M. (2011). Diagnóstico dos impactos socioambientais no manguezal do Rio Acaraú (Ceará- 
Brasil) devido à carcinicultura. (Dissertação de mestrado). Retrieved from https://repositorioaberto.up.pt/bitstream/10216/20015/2/Dissertao\%20\%2 0Dbora\%20Maria\%20Amorim.pdf.

Araripe, H. G. D. A., Lopes, J. B., \& Bastos, M. E. G. (2006). Aspectos do licenciamento ambiental da carcinicultura na APA do Delta do Parnaíba. Ambiente \& Sociedade, 9 (2), 143-173.

Araruna, R. P. L., Soares, M. O. (2017). Efetividade de manejo em unidade de conservação com manguezais: estudo de caso no litoral do Ceará, nordeste do Brasil. Geosaberes: Revista de Estudos Geoeducacionais, 8(16), 53-68.

Araújo, I. M. M., Nascimento, M. M. B., Oliveira, A. G. R. C. (2016). Recursos hídricos e saúde humana: impactos industriais e estratégias de manejo e proteção ambiental no município de Goiana/PE. INTERthesis: Revista Internacional Interdisciplinar, 13(3), 163-181.

Azevêdo, V. C. S. (2005). Carcinicultura: parâmetros integrativos como instrumentos de prevenção de impactos. (Dissertação de Mestrado). Retrieved from: https://repositorio.ufba.br/ri/handle/ri/21693.

Bento, E. S. (2012). Aspectos etnoecológicos da carcinicultura no Parque dos Manguezais e llha de Deus. (Dissertação de mestrado). Retrieved from https://repositorio.ufpe.br/handle/123456789/10565

BRASIL. Lei $n .12 .651$, de 25 de maio de 2012. Novo Código Florestal. Diário Oficial [da] República Federativa do Brasil, Brasília, DF, 25 maio 2012. Retrieved from:http://www.planalto.gov.br/ccivil 03/ ato20112014/2012/lei//12651.htm. Acesso em: 10 maio 2018.

Carneiro, M. A. B., Farrapeira, C. M. R., Silva, K. M. E. (2008). O manguezal na visão etnoecológica dos pescadores artesanais do Canal de Santa Cruz, Itapissuma, Pernambuco, Brasil. Biotemas, 21(4), 147155.

Carvalho, R. A. A., \& Martins, P. C. C. (2017). Caracterização da atividade de carcinicultura no vale do rio Açu, Rio Grande do Norte, Brasil. Holos, (3) 2, 96-107.

CONAMA. Conselho Nacional do Meio Ambiente.

Resolução CONAMA No 312 de 10 de outubro de 2002. Dispõe sobre parâmetros, definições e limites de Áreas de Preservação Permanente. Diário Oficial [da] República Federativa do Brasil, Brasília, DF, 18 out. 2002. Retrieved from

http://www2.mma.gov.br/port/conama/legiabre.cfm?codl egi=334>. Acesso em: 5 dez. 2018.

D'angelis, I. \& Moura, G. F. (2016). O cenário social, econômico e ambiental da pesca artesanal em uma comunidade no litoral paraibano. REDE - Revista Eletrônica do PRODEMA, 10(2), 62-75.

Dias, H. M., Soares, M. L. G., Neffa, E. (2012). Conflitos socioambientais: o caso da carcinicultura no complexo estuarino Caravelas-Nova Viçosa/BahiaBrasil. Ambiente \& Sociedade, 15(1), 111-130.

Donato, D. C., Kauffman, J. B., Murdiyarso, D., Kurnianto, S., Stidham, M., Kanninen, M. (2011). Mangroves among the most carbon-rich forests in the tropics. Nature geoscience, 4(5), 293-297.

Elfes, C. T., Longo, C., Halpern, B. S., Hardy, D., Scarborough, C., Best, B. D., Dutra, G. F. (2014). A regional-scale ocean health index for Brazil. PLoS One, 9(4), e92589.

Fabiano, R. B. (2004). Conflitos socioambientais e gestão integrada e sustentável de recursos pesqueiros: estudo de caso sobre a atividade de carcinicultura na área da Lagoa de Ibiraquera (municípios de Imbituba e Garopaba-SC). (Dissertação de mestrado). Retrieved fromhttps://repositorio.ufsc.br/bitstream/handle/123456 789/87791/212670.pdf?sequence=1

Fernandez, J. I. V. (2015). A política nacional de desenvolvimento sustentável da pesca e da aquicultura e seus impactos sobre a pesca artesanal no Estado de Pernambuco. (Dissertação de mestrado) Retrieved from

https://repositorio.ufpe.br/handle/123456789/14026

Ferreira, D. M., Melo, J. V., Costa Neto, L. X. (2008). Influência da carcinicultura sobre a salinização do solo em áreas do município de Guamaré/RN. Holos, (2), 7280.

Figueirêdo, M. C. B., Rosa, M. F., Godim, R. S. (2003). Sustentabilidade ambiental da carcinicultura no Brasil: desafios para a pesquisa. Revista Econômica do Nordeste, 34(2), 242-253.

Galli, O. B., Fujimoto, R. Y., \& Abrunhosa, F. A. (2012). Acute toxicity of sodium metabisulphite in larvae and post-Larvae of the land crab, Cardisoma guanhumi. Bulletin of environmental contamination and toxicology, 89(2), 274-280.

Godoy, M. D. P., Lacerda, L. D. (2014). River-island morphological response to basin land-use change within the Jaguaribe River estuary, NE Brazil. Journal of Coastal Research, 30(2), 399-410.

Godoy, M. D. P., Meireles, A. J. A, Lacerda, L. D. (2018). Mangrove Response to Land Use Change in Estuaries along the Semiarid Coast of Ceará, Brazil. Journal of Coastal Research, 34(3), 524-533.

Gomes, E. J. S., Batista, I. S., Lima, Z. M. C. (2018). Cobertura, ocupação do solo e erosão no entorno da Laguna Guaraíras/RN, Brasil. HOLOS, 1, 140-156. 
Guimarães, A. S. (2007). Análise multitemporal da superfície de manguezal do Litoral norte de Pernambuco: a participação da aqüicultura na conversão de áreas de mangue em viveiro. (Dissertação de mestrado) Retrieved from http://www.dominiopublico.gov.br/pesquisa/DetalheObr aForm.do?select_action=\&co_obra $=45365$

ICMBIO - Instituto Chico Mendes de Conservação da Biodiversidade. (2018). Atlas dos manguezais do Brasil. Retrieved from

https://www.icmbio.gov.br/portal/ultimas-noticias/20geral/9581-icmbio-lanca-atlas-dos-manguezais-dobrasil

Jeronimo, C. E. Balbino, C. P. (2012). Caracterização físico-química de efluentes da carcinicultura e seus impactos ao meio ambiente. Rev. Elet. em Gestão, Educação e Tecnologia Ambiental, 8(8), 1639-1650.

Joventino, F. K. P., Mayorga, M. I. D. O. (2008). Diagnóstico socioambiental e tecnológico da carcinicultura no município de Fortim, Ceará, Brasil. REDE-Revista Eletrônica do PRODEMA, 2(1), 80-96.

Laurentino, I. C., SOUZA, S. C. (2013). Uma análise do plano de recuperação de área degradada com vegetação de mangue no rio Apodi Mossoró do projeto margem viva. HOLOS, 3, 161-170.

Leitão, R. C., Cavalcante, R. R., Ribeiro, E. M., Claudino, R. L., Maciel, N. M., \& Rosa, M. D. F. (2011). Reúso da água da despesca na produção de camarão. Revista Brasileira de Engenharia Agrícola e Ambiental, 15(12), 1314-1320.

Lima, M. E. A. (2016). Gestão participativa na reserva extrativista Acaú-Goiana: o papel da comunidade de Acaú-PB. 2016. (Dissertação de mestrado). Retrieved from http://repositorio.ufpe.br/handle/123456789/17429

Little, P.E. Os conflitos socioambientais: um campo de estudo e de ação política. (2001). In: Bursztyn, M. (Org.) A difícil sustentabilidade: política energética e conflitos ambientais. 107-122. Rio de Janeiro:

Garamond.

Loureiro, C. V., Gorayeb, A. (2013). O Turismo comunitário como alternativa para a preservação dos ecossistemas litorâneos: 0 caso da Comunidade de Curral Velho, Acaraú-CE-Brasil. Revista de Turismo Contemporâneo, 1(1), 1-17.

Malik, A., Fensholt, R., Mertz, O. (2015). Mangrove exploitation effects on biodiversity and ecosystem services. Biodiversity and conservation, 24(14), 35433557.

Meireles, A. J. A., Cassola, R. S., Tupinambá, S. V., Queiroz, L. S. (2007). Impactos ambientais decorrentes das atividades da carcinicultura ao longo do litoral cearense, nordeste do Brasil. MercatorRevista de Geografia da UFC, 6(12), 83-106.

Miranda, A. M., Alencar, V. B., Silva, E. V. (2016). 0 papel da educação ambiental nos conflitos socioambientais do litoral cearense: o ecossistema manguezal em foco. In: VIII Fórum Internacional de Pedagogia. Universidade Federal do Maranhão. Imperatriz.

Moreira, J. F., Andrade, M. O. (2010). O conflito de competências na gestão pública de uma APA: 0 caso da APA da Barra do Rio Mamanguape - PB. Gestão Pública: Práticas e Desafios, 1(1), 242-263.

Moreira, L. E. B., Lombardi, J. V., Mercante, C. T. J., Bazante-Yamaguishi, R. (2018). Análise ecotoxicológica em viveiro de carcinicultura de água doce, utilizando o cladócero Ceriodaphnia dubia como organismo-teste. Boletim do Instituto de Pesca, 36(1), 25-38.

Mota, D. M. D., Schmitz, H., \& Silva-Júnior, A. D. (2015). (Des) acordos quanto ao uso dos recursos naturais em um contexto de transformação fundiária em Sergipe. Ambiente \& Sociedade, 18(2), 41-58.

Motta-Sobrinho, M. A., Andrade, A. C. (2011). 0 desafio da conservação de manguezais em áreas urbanas: identificação e análise de conflitos socioambientais no Manguezal do Pina-Recife-PEBrasil. Unimontes Científica, 11(1/2), 8-16.

Natori, M. M., Sussel, F. R., Santos, E. D., Previero, T. C., Viegas, E. M. M., \& Gameiro, A. H. (2011). Desenvolvimento da carcinicultura marinha no Brasil e no mundo: avanços tecnológicos e desafios. Informações econômicas, 41(2), 61-73.

Nóbrega, G. N., Ferreira, T. O., Romero, R. E., Marques, A. G. B., Otero, X. L. (2013). Iron and sulfur geochemistry in semi-arid mangrove soils (Ceará, Brazil) in relation to seasonal changes and shrimp farming effluents. Environmental monitoring and assessment, 185(9), 7393-7407.

Oliveira, G. D., Mattos, K. M. C. (2007). Impactos ambientais provocados pela indústria de camarão no município de Nísia Floresta (RN). Revista Ibero Americana de Estratégia, 6(2), 183-188.

Pedale, A. B., Fujimoto, R. Y., Santos, R. F., Abrunhosa, F. A. (2012). Acute toxicity of sodium metabisulphite on mangrove crab Ucides cordatus (Decapoda, Ucididae). Anais da Academia Brasileira de Ciências, 84(4), 1009-1014.

Pinto, M. F., Nascimento, J. L. J., Alves, R. R. N, \& Meireles, A. J. (2013). Qual a relação entre etnozoologia e território? Revista Ouricuri, 3(2), 068088. 
Rocha, I.P. (2015). Cultivo do Camarão Marinho: Atividade Socialmente Justa, Ambientalmente Responsável e, Economicamente Importante, de Forma Especial para o Meio Rural da Região Nordeste. Associação brasileira dos criadores de camarão (ABCCAM). Público. Retrieved from http://abccam.com.br/2015/05/cultivo-do-camaraomarinho-atividade-socialmentejusta-ambientalmenteresponsavel-e-economicamente-importante-de-

Rodrigues, G.G., Souza, A. E. V. N., Lima, M. E. A., Neto, I. R. G. C., da Silva Leite, J. K., Nascimento, D. M., Harder, E., Castro, A. E. (2017). Território, paisagens e identidades culturais em uma reserva extrativista marinha do Nordeste brasileiro. Revista Movimentos Sociais e Dinâmicas Espaciais, 6(1), 235242.

Sampaio, Y., Costa, E. D. F., Sampaio, E. A. B. R. (2008). Impactos socioeconômicos do cultivo de camarão marinho em municípios selecionados do Nordeste brasileiro. Revista de Economia e Sociologia Rural, 46(4), 1015-1042.

Santos, H. V. S., Santos, T. O., Holanda, F. S. R. (2016). Indicadores para diagnóstico das alterações antrópicas no manguezal do estuário do rio São Francisco. Tropical Oceanography, 39 (2), 166-178.

Silva, C. N. (2009). A carcinicultura na área de proteção ambiental da barra do rio mamanguape: 0 caso do empreendimento da destilaria miriri. (Trabalho de
Conclusão de Curso). Universidade Federal da Paraíba.

Silva, L. H. A. (2011). Reflexões sobre a política de conservação ambiental e a criação de unidades de conservação na Cidade do Recife: o Parque Natural Municipal dos Manguezais Josué de Castro. (Dissertação de mestrado). Retrieved from https://repositorio.ufpe.br/handle/123456789/2858

Silveira, P. C. B., Mesquita, B., Melo, L., \& Oliveira Filho, I. (2013). Estuário, paisagem-fluxo de pescadores artesanais. Iluminuras, 14(34).

Silvestre, L. C., Farias, D. L. S., Lourenço, J. D. S., Barros, S. C. A., \& Braga, N. M. P. (2011). Diagnóstico dos impactos ambientais advindo de atividades antrópicas na APA da Barra do Rio Mamanguape. Enciclopédia Biosfera, Centro Científico ConhecerGoiânia, 7(12), 1-11.

Tancredo, K. R., Nobrega, R. O., Dias, T., Lapa, K. R. (2011). Impactos ambientais da carcinicultura brasileira. In: 3rd International Workshop Advances in Cleaner Production: Cleaner Production Initiatives and Challenges for a Sustainable World. Universidade Paulista, São Paulo.

Tuna, F. A. P., \& Tagliolatto, A. B. (2015). Um breve panorama abordando aspectos positivos e negativos da maricultura. Revista IPTEC, 3(1), 127-136. 